\title{
LAS POLÍTICAS AGRARIAS EN TÚNEZ, ARGELIA Y MARRUECOS Y LA SEGURIDAD ALIMENTARIA
}

\author{
Javier Ignacio García ${ }^{1}$ Universidad IE / UNISCI, Patricia Rodríguez ${ }^{2}$ \\ Periodista / UNISCI, Mónica Miranzo ${ }^{3}$ UNISCI.
}

\begin{abstract}
Resumen:
El artículo analiza las políticas agrícolas contemporáneas de Túnez, Argelia y Marruecos. El artículo describe las políticas agrícolas de estos tres países del Norte de África y explica su desarrollo en las últimas décadas. Se estudia el diseño y objetivos de estas políticas y los resultados -positivos y negativos- que han obtenido en términos de modernización del sector agrario, incrementos de producción y productividad, así como su adecuación a un nuevo contexto de creciente globalización y liberalización de los mercados internacionales de productos agrarios en el marco de la OMC y los acuerdos con la Unión Europea. La Seguridad Alimentaria aparece como un objetivo fundamental de las políticas agrícolas de estos tres países del Magreb. En este sentido, el artículo analiza los diferentes instrumentos y medidas de oferta y demanda que estos países han puesto en marcha para intentar conseguirlo, con resultados positivos en algunos casos, pero sin cumplir los objetivos previstos en otros.
\end{abstract}

Palabras clave: Políticas Agrícolas, seguridad alimentaria, seguridad, Magreb, Túnez, Argelia, Marruecos.

Title in English: "Food Security and Agrarian Policies in Tunisia, Algeria and Morocco”

Abstract:

This article analyzes the contemporary agricultural policies in Tunisia, Algeria and Morocco. The article describes the agricultural policies of these North African countries and explains their developments and objectives in recent decades. We also examined the positive and negative results obtained in terms of modernization of the agricultural sector, increase in production and productivity, as well as its adaptation to a new context of increasing globalization and international market liberalization of agricultural products in the frame of the WTO and the agreements with the European Union. Food security appears as a fundamental objective of the agricultural policies of these Maghreb countries. In this sense, the article analyzes the different instruments and measures on supply and demand that these countries have implemented, with positive results in some cases but without reaching the target in others.

Keywords: Agricultural Policies, Food Security, Security, Tunisia, Algeria, Morocco, Maghreb.

Copyright @ UNISCI, 2013.

Las opiniones expresadas en estos artículos son propias de sus autores, y no reflejan necesariamente la opinión de UNISCI. The views expressed in these articles are those of the authors, and do not necessarily reflect the views of UNISCI.

\footnotetext{
${ }^{1}$ El Dr. Javier Ignacio García González es profesor de relaciones internacionales, globalización y ciencias políticas en la Escuela de Comunicación de la Universidad IE, es investigador senior de UNISCI y miembro del Foro Hispano-Argelino.

Dirección: Escuela de Comunicación, Universidad IE, Campus de Santa Cruz la Real, C/ Cardenal Zúñiga 12 , 40003 Segovia, España

E-mail: javier.garcia@ie.edu.

${ }^{2}$ Patricia Rodríguez Blanco es periodista, investigadora de UNISCI y miembro del Foro Hispano-Argelino.

E-mail: rodriguez.blanco@gmail.com.

${ }^{3}$ Mónica Miranzo Proi es investigadora junior de UNISCI y miembro del Foro Hispano-Argelino.

E-mail: mmiranzop@yahoo.es.
}

http://dx.doi.org/10.5209/rev_UNIS.2013.n31.4470 


\section{Introducción: El estado de la cuestión}

Un análisis de la seguridad alimentaria en los países del Magreb tiene necesariamente que pasar por la revisión de las políticas agrícolas que los distintos gobiernos de la región han desarrollado como parte de sus distintos programas de desarrollo político y económico. El riesgo de inseguridad alimentaria y la fragilidad de las zonas rurales en países como Túnez, Argelia y Marruecos son elementos que tradicionalmente han sido tenidos en cuenta a la hora de explicar la evolución económica, política y social de la región, y de modo alguno deben ser olvidadas en la actualidad, en un contexto internacional en evolución -caracterizado por las tendencias liberalizadoras de los mercados internacionales y por una creciente globalizacióny con un contexto regional cuando menos convulso para estos países en los últimos años, en el que los resultados de las revueltas de la llamada "primavera árabe" están todavía por determinar.

Si bien los acontecimientos político-sociales ocurridos en la región desde finales de 2010 no podemos atribuirlos específicamente a problemas derivados de la carencia o escasez de alimentos, sino a problemas más complejos de insatisfacción en los que se entremezclan sentimientos de exclusión social, económica y territorial junto a reivindicaciones políticas y de reconocimiento de la dignidad ${ }^{4}$, la inseguridad alimentaria y esa situación de falta de desarrollo en las áreas rurales a la que hacíamos referencia se pueden convertir en potentes catalizadores del descontento y las reivindicaciones sociales.

La situación del campo en el norte de África, y particularmente el tema de la seguridad alimentaria, se convierten así en elementos esenciales para analizar la evolución política, económica y social de los distintos países, lo que reconocen en principio los propios gobiernos de la región al diseñar, aprobar e implementar -si es el caso-, las respectivas políticas agrícolas que analizaremos a continuación. ¿Hasta qué punto el diseño de estas políticas responde a las necesidades reales de estos países y sus poblaciones? ¿Nos encontramos ante políticas coherentes y realistas, y no ante declaraciones de "buenos deseos" fundamentalmente de carácter retórico? ¿Han resultado eficaces estas políticas a la hora de cumplir esos objetivos de seguridad alimentaria y de modernización y adaptación de las agriculturas nacionales al nuevo contexto internacional? A estas cuestiones básicas y sus derivadas intentaremos dar respuesta a continuación con la descripción y análisis de las políticas agrícolas en Túnez, Argelia y Marruecos.

\section{El caso de Túnez}

La evolución económica y social de Túnez en las últimas décadas ha convertido un país eminentemente agrícola a finales de los años 60 en un Estado con una economía mucho más diversificada, con un sector terciario que suponía en 2011 casi el 60\% de la producción nacional, una industria cuya aportación al PIB está alrededor del $31 \%^{5}$ y con una participación del sector agrario que ha descendido notablemente en las últimas décadas, pasando de constituir alrededor del 30\% del PIB hace 50 años, a un 16,5\% en $1996^{6}$ (agricultura y pesca),

\footnotetext{
${ }^{4}$ Abis, Sébastien (2012): Pour le Futur de la Méditerranée: L’Agriculture, L'Harmattan, p. 7.

${ }^{5}$ Datos del Instituto Nacional de Estadística de Túnez en ICEX (2012): Guía País de Túnez 2012, pp. 10-13.

${ }^{6}$ République Tunisienne (2000): Le Dixieme Plan de Développement 2002-2006, vol. 1, p. 32.
} 
el $12,6 \%$ del PIB en $2007^{7}$ y algo menos del $10 \%$ en la actualidad ${ }^{8}$, con una previsión de que suponga en 2014 alrededor del $8,2 \%^{9}$.

Pese a esta clara reducción del peso del sector primario en la economía, la agricultura sigue siendo un sector económico de gran relevancia para Túnez, que proporciona una parte esencial de la alimentación del país, ocupa cerca del $20 \%$ de la mano de obra activa total y supone alrededor del $14 \%$ de las exportaciones globales de ese Estado ${ }^{10}$. En ese sentido, la agricultura recibirá por parte del gobierno de Túnez una atención similar a otros sectores, y las políticas públicas agrarias se incluirán junto a las de los otros ámbitos de la economía en los sucesivos Planes de desarrollo económico y social elaborados por las autoridades. De un modo general, estas políticas han fomentado un desarrollo agrícola que se ha producido en términos de incremento de la producción y de mejora de la disponibilidad alimentaria con resultados remarcables ${ }^{11}$, pero que revelan signos serios de fragilidad y límites ciertos ${ }^{12}$ de los que hablaremos más adelante.

La agricultura tunecina sobre la que se proyectan los planes de desarrollo continúa siendo en la actualidad básicamente una agricultura de pequeñas explotaciones. El $87 \%$ de las explotaciones agrarias tiene una superficie menor de 20 hectáreas (has.) ${ }^{13}$ y el $75 \%$ inferior a 10 , lo que da lugar a una estructura agraria muy atomizada en la que la media del tamaño de las explotaciones no supera las 10-11 has.. La evolución en las últimas décadas ha acrecentado esa tendencia, con un incremento del número de explotaciones y la consecuente disminución del tamaño medio de las explotaciones familiares ${ }^{14}$, aunque las sucesivas políticas agrícolas han fomentado la creación de algunas grandes explotaciones dedicadas fundamentalmente a cereal ${ }^{15}$.

Del conjunto de las tierras cultivables, la superficie de regadío se sitúa alrededor de las 400 mil has., es decir, sobre el $8 \%$ de la superficie agrícola útil total ${ }^{16}$. Desde el punto de vista geográfico y territorial, esta estructura genera dos dinámicas agrícolas muy distintas y separadas entre sí: por una parte regiones relativamente más dinámicas y productivas, fundamentalmente por su disponibilidad de agua para riego -aunque también con muchas explotaciones de pequeño tamaño- y, de otra parte, las zonas con sistemas agrícolas mucho más tradicionales y de producción débil, formadas por pequeñas parcelas poco insertadas en el mercado ${ }^{17}$, que suponen la mayoría del campo tunecino.

En cuanto a la producción agropecuaria en Túnez, no ha cesado de aumentar desde 1990, aunque esta progresión no ha sido regular sino muy dependiente de las condiciones meteorológicas $^{18}$. Aunque la pluviometría determina en buena medida los resultados anuales

\footnotetext{
7 Ministère de L'Agriculture et des Ressources Hydrauliques (2007): XIème Plan de Développement (20072011), p. 22.

${ }^{8}$ Laajimi, A.; Thabet, B. y Ben Said, Moncet: "Une lecture Dans la politique agricole et alimentaire en Tunisie: Pour une nouvelle vision", New Medit, no 2 (2012), p. 24.

${ }^{9}$ République Tunisienne (2009): XIIème Plan de Développement 2010-1014, p. 88

${ }^{10}$ Banque Africaine de Développement (2012): "Distorsions aux incitations et politique agricole en Tunisie: une première analyse", Note Economique BAD, p. 1.

${ }^{11}$ CIHEAM (2009): "Perspectives des politiques agricoles en Afrique du Nord", Options Méditerranéennes, $\mathrm{n}^{\circ}$ B64, p. 59.

${ }^{12}$ Laajimi et al. op.cit. p. 24.

13 "XIème Plan...", op.cit., p. 25.

${ }^{14}$ Laajimi et al., op.cit. p. 24.

15 "Perspectives des politiques agricoles en Afrique du Nord...", op.cit., p. 78.

16 "XIème Plan...", op.cit., p. 20.

${ }^{17}$ Laajimi et al., op.cit. p. 24.

18 "Distorsions...", op.cit., p. 5.
} 
concretos, es ilustrativo que durante el periodo 2004-2007 la estructura de la producción ${ }^{19}$ mostraba cómo la ganadería suponía el $37 \%$ de la producción total, seguida de un $21 \%$ de cultivos arbóreos (aceituna, dátil, cítricos), un 16\% de horticultura, un 14\% de cereales, un $6 \%$ de pesca y productos marinos y el resto en productos diversos. Esta producción hacía posible unas exportaciones de productos agroalimentarios (26\% del PIB agrícola total) centradas fundamentalmente en aceite de oliva, dátiles y productos del mar, con otros productos muy diversos en mucha menor medida ${ }^{20}$. Por lo que respecta a importaciones, entre otros productos Túnez importa cantidades importantes de azúcar (11\%), aceite de semillas (20\%) y, en particular, cereales, que suponen regularmente entre un $40 \%$ y un $50 \%$ de las importaciones de productos agrarios totales ${ }^{21}$. Túnez se configura por tanto como un país con una fuerte dependencia alimentaria de este tipo de producto ${ }^{22}$ básico para la alimentación de la población. En concreto, en el periodo 2005-2012, entre el 55 y el $70 \%$ de cereales consumidos en Túnez procedía de las importaciones, llegando a un pico del $80 \%$ de cereal importado en 2007, indicando el fuerte grado de dependencia exterior en estos productos ${ }^{23}$.

La balanza comercial de intercambios alimentarios entre 1995 y 2009, fuertemente deficitaria hasta 2003, comenzó a partir de ese año a cambiar de tendencia principalmente por los incrementos de exportaciones, notablemente mayores que el incremento de importaciones que también se ha producido desde comienzos de los años 2000. Cerca de tres cuartas partes de estos intercambios de productos agroalimentarios se producen en la actualidad son con la Unión Europea $^{24}$.

\subsection{Las políticas agrarias de Túnez y los Planes quinquenales de desarrollo económico y social}

Los sucesivos planes globales de desarrollo preparados por los gobiernos de Túnez han incluido entre sus planteamientos los que han sido los ejes principales del desarrollo del sector agrario en los últimos tiempos. La firma del acuerdo de partenariado con la Unión Europea en el año 2000, durante el periodo de vigencia del IX Plan de desarrollo, supuso un revulsivo que aceleró el ritmo de ejecución de las políticas y reformas definidas en ese momento ${ }^{25}$, dirigidas fundamentalmente a los ámbitos de reestructuración de tierras comunales, iniciativas de mejora de la productividad (un objetivo constante en Planes anteriores y posteriores), al refuerzo del tejido de agrupaciones interprofesionales, a estrategias de aprovechamiento de recursos hidráulicos y agua potable, mejoras de infraestructuras hidráulicas e incremento de tierras en regadío (30.000 has. en el periodo 1997-2001), así como el desarrollo de estrategias para intentar conseguir la autosuficiencia en productos básicos. Los resultados en términos cuantitativos de estas reformas, aunque supusieron crecimientos menores de los previstos desde un punto de vista global ${ }^{26}$, consiguieron incrementos de producción significativos en la

\footnotetext{
${ }^{19}$ Portail de l'Agriculture en Tunisie (sitio oficial): "Structure de la production agricole (moyenne de la période 2004-2007)", (Dic. 2012) en www.agriportail.tn; Los datos pueden varían de año en año dependiendo de factores como las cosechas, clima, pluviometría, etc. pero son perfectamente válidos para tener una visión general de la estructura actual de la producción.

${ }^{20}$ Salah Bachta, Mohamed (2008): Tunisie. L'agriculture, l'agro-alimentaire, la pêche et le développement rural, Monographies du CIHEAM, p. 78.

${ }^{21}$ Ibid, p. 79.

${ }^{22}$ Laajimi et al., op. cit. p. 24.

${ }^{23}$ Hallam, David y Balby, Liliana: "Cereals Price Volatility and Food Security in the Mediterranean Area", CIHEAM Watch Letter, $\mathrm{n}^{\circ}$ 23, (Dic. 2012), p. 10.

24 "Distorsions...", op.cit, p. 6.

25 "Le Dixième Plan...", op. cit., p. 4.

${ }^{26} 2,6 \%$ de crecimiento real frente al 4,3\% previsto, según se recoge en "Le Dixieme Plan...", op. cit., p. 6.
} 
mayor parte de los productos agropecuarios locales, con la excepción de los cereales ${ }^{27}$, mientras que se produjeron algunas mejoras muy moderadas en el entorno productivo en el que los agricultores desarrollaban su actividad.

El X Plan 2002-2006, como señala el mismo documento que lo presenta, descansará sobre la base del plan anterior e intentará superar los problemas surgidos a la hora de concretar determinados objetivos del plan anterior, deficiencia que se reconoce explícitamente ${ }^{28}$.

De forma más precisa, la estrategia definida en el nuevo Plan se diseña con los siguientes objetivos ${ }^{29}$ : 1.- Asegurar la seguridad alimentaria del país; 2.- reforzar la competitividad del sector; 3.- movilización y explotación de recursos naturales disponibles; 4.- mejora de los ingresos del agricultor y la mejora de los recursos humanos. Es significativo que entre estos objetivos no se mencione de un modo explícito el sector de las exportaciones agrarias -principalmente procedente de excedentes y no de producción agraria destinada a la exportación-, sino que todos los objetivos se centrarán principalmente en el desarrollo del campo y de la producción agraria para satisfacer las demandas internas. La mención a los productos de exportación (aceite de oliva, dátiles y productos de la mar principalmente) aparecerá sólo para hablar del incremento en su producción, pero no como parte de una estrategia integrada. No obstante, la evaluación posterior de los resultados del X Plan sí se referirá a la puesta en práctica durante este periodo de medidas destinadas a fomentar la cultura de "producir para la exportación" ${ }^{30}$, ausente hasta el momento en la mayor parte de los productores tunecinos.

Los ejes de actuación que se proponen para la consecución de estos objetivos abarcan múltiples ámbitos que van desde la mejora de la rentabilidad económica, de la competitividad, mejoras tecnológicas y de investigación científica, mejoras regulatorias y legales, divulgación y formación de los agricultores, política de precios basada en la liberalización durante todas las etapas pero manteniendo el equilibrio en los mercados en caso de excedentes (lo que supone cierta contradicción), desarrollo de estructuras profesionales, lucha contra la sequía, reestructuración de tierras comunales, mejoras en las grandes explotaciones, etc. En definitiva toda una serie de líneas de actuación muy extensas dirigidas básicamente a incrementar la producción y a una mejora general del contexto de trabajo del agricultor.

Merece la pena destacar la pretensión de mejorar los ingresos de los productores agrarios como uno de los factores esenciales para la inversión agrícola y para el mantenimiento de los agricultores en las zonas rurales ${ }^{31}$. No obstante, la visión de la agricultura en este plan la considera como un sector económico aislado, sin relación con otros elementos que en los últimos años son comunes al analizar la situación del campo en otros contornos, tales como las políticas de desarrollo rural - referidas a potenciación de actividades no específicamente agrícolas- o el desarrollo de las infraestructuras de las zonas rurales -sólo se habla de las hidráulicas, no de otras mejoras en comunicación o transportes-, fundamentales para integrar las producciones agrarias en los mercados.

El XI Plan de Desarrollo (2007-2011) pretenderá dar un nuevo impulso a un sector agrario como el tunecino que ya no es exclusivamente "local" y que cada vez está más

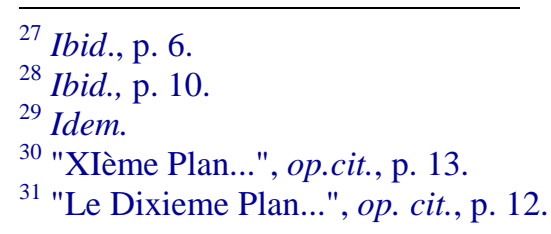


presionado por un contexto internacional caracterizado por la tendencia a la liberalización del comercio de productos agrícolas, ya sea a nivel bilateral con la Unión Europea ya sea a nivel global en el marco de la Organización Mundial de Comercio ${ }^{32}$. Así, el principal desafío del nuevo Plan será abordar la adaptación del campo tunecino a este nuevo contexto de liberalización creciente de los mercados, que se considera como una oportunidad para exportar algunos productos pero que, desde un punto de vista nacional, debe ser capaz de "consolidar la seguridad alimentaria del país y plantar cara a las mutaciones cualitativas que conoce la demanda de alimentos, diversificando la producción y adaptándose a las necesidades de los mercados" ${ }^{33}$.

Desde esta premisas se establecerá la nueva política agraria tunecina para el decenio 2007-2016 ${ }^{34}$, iniciada en el periodo del XI Plan de desarrollo sectorial de agricultura y pesca (2007-2011), pero que mantendrá la continuidad en sus líneas básicas en el XII Plan de desarrollo del Gobierno de Túnez para el periodo (2010-2014) ${ }^{35}$, como se refleja en el capítulo que dedica al sector agrario. De este modo, la política agrícola tunecina en los últimos años se ha centrado en cuatro pilares esenciales ${ }^{36}$, algunos de ellos ya conocidos de planes anteriores: 1.- mejora de la competitividad del sector; 2.- promoción de las exportaciones de productos en tanto que motor de crecimiento; 3.- promoción de recursos naturales en tanto que base fundamental de un desarrollo agrícola duradero; 4.- finalmente, aunque igual o más importante que los anteriores, la consolidación de la seguridad alimentaria en tanto que vector de soberanía nacional.

La mejora de la competitividad contemplada en este Plan se inscribe ya en la lógica de liberalización de la economía, de la que no escapa el campo tunecino, y de su inserción en una economía mundial cada vez más globalizada, que exigirá una nueva redistribución de recursos y nuevas orientaciones de las políticas agrarias ${ }^{37}$. Las medidas en este ámbito ${ }^{38}$ buscarán así mejoras prácticamente en todos los aspectos ya recogidos en Planes anteriores como la aceleración del ritmo de crecimiento de la agricultura, conseguir una estructuración moderna del sector (territorial, tamaño de explotaciones, tierras comunales, inversiones y financiación, seguros, recursos humanos, investigación, enseñanza, formación del agricultor, organizaciones profesionales, modernización de pequeñas y medianas explotaciones, etc.). La elaboración de una nueva estrategia de investigación agrícola será uno de los objetivos específicos que se recogerán en el XII Plan ${ }^{39}$, junto a medidas de reforma agraria, de estructuración profesional del sector (siempre pendientes) y de complementariedad del sector productivo con la industria de transformación.

La potenciación de las exportaciones agrícolas se configura como un objetivo fundamental en el nuevo contexto internacional en el que se inscribe la economía del país, que tendrá un carácter prioritario y estratégico por su papel tanto en el equilibrio de la balanza comercial agroalimentaria como en la balanza de pagos ${ }^{40}$. Preparar el sector para la creciente liberalización y apertura de los mercados, la promoción de la calidad y de la competitividad, así como la diversificación de productos adecuados para exportar serán ejes esenciales de esta

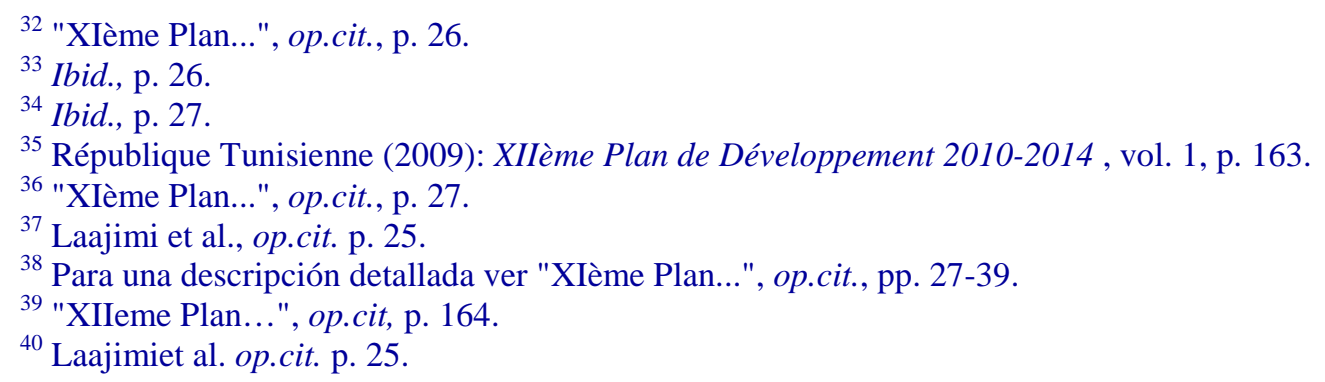


política $^{41}$. Esta diversificación será uno de los objetivos principales señalados para el periodo del XII Plan ${ }^{42}$, junto con la recurrente intensificación de la producción.

La consideración de los recursos naturales como base fundamental del desarrollo agrario no es una novedad en el diseño de las políticas agrarias de los sucesivos planes de desarrollo, de manera que ya se contemplaron en su momento estrategias referentes al agua, las tierras agrícolas, los bosques y pastos o los recursos marinos ${ }^{43}$. El XI Plan contempla dar un paso más allá adoptando una visión global e integradora de las distintas estrategias sectoriales, con la meta de una promoción y gestión de estos recursos de forma duradera y, al menos sobre el papel, sostenible ${ }^{44}$, preservando la soberanía sobre ellos. La mejora y optimización de las tierras regables, mejoras técnicas, políticas de reforestación o de lucha contra la desertificación aparecen citadas como principales ejes de acción en este ámbito en los dos planes del decenio. En este sentido, el XII Plan señala de forma explícita su pretensión de seguir concretando y actualizando las diferentes estrategias iniciadas en el periodo anterior $^{45}$

El último objetivo señalado en los Planes de desarrollo -o eje según la denominación del XII Plan-, será la consolidación de la seguridad alimentaria ${ }^{46}$, considerada como una opción estratégica constante y un objetivo fundamental del esfuerzo de desarrollo de Túnez, definido de este modo como un "vector de la soberania nacional"47.

La cuestión de la seguridad alimentaria se introdujo como objetivo número uno en el VII Plan de desarrollo, como evolución del antiguo objetivo de seguridad alimentaria ${ }^{48}$. Desde entonces los sucesivos Planes lo han mantenido como objetivo prioritario de las políticas agrarias, en particular la necesidad de incrementar cada vez más la producción y la $\operatorname{productividad}^{49}$, es decir sobre todo medidas en el ámbito de la oferta. Los progresos económicos, los aumentos de producción que se han ido logrando, la mejora de la capacidad adquisitiva de la población y el incremento en la oferta y variedad de productos han permitido una situación que oficialmente se considera de "alto nivel de seguridad alimentaria",50, es decir, resultado de "la abundancia de la producción agrícola nacional", y que aparece también ligada en los documentos a la mejora de los ingresos de los pequeños agricultores y a la oferta de empleo en zonas rurales.

De hecho, la seguridad alimentaria se reconoce que está indisociablemente ligada a las dimensiones económica y social de la política de desarrollo de Túnez. En este sentido, en el periodo actual se pretende avanzar en un desarrollo agrícola duradero y sostenible, así como mejorar los ingresos y las condiciones de vida del agricultor como parte de esa política de seguridad alimentaria. El apoyo a los productores y la garantía de disponibilidad de los inputs agrarios (semillas, abonos, fitosanitarios) se contemplan como parte de esa política de seguridad alimentaria ${ }^{51}$. El mayor desarrollo de la producción, los regadíos, nuevas técnicas de producción, mejoras en la comercialización (antes olvidadas) son áreas donde se plantean

\footnotetext{
41 "XIème Plan...", op.cit., p. 40; "XIIème Plan...", op.cit., p. 163.

42 "XIIeme Plan...", op.cit, p. 165.

43 "XIème Plan...", op.cit., p. 41.

${ }^{44}$ Laajimi et al. op.cit. p. 42.

45 "XIIeme Plan...", op.cit,, p. 166.

${ }^{46}$ Ibid., p. 163.

47 "XIème Plan...", op.cit., p. 45.

${ }^{48}$ Laajimi et al. op.cit. p. 25.

49 "XIIème Plan...", op.cit, p. 163.

50 "XIème Plan...", op.cit., p. 45.

51 "XIIeme Plan...", op. cit. p. 163.
} 
mejoras, así como incrementar la producción y exportación de los productos en los que Túnez es competitivo, intentando así equilibrar la balanza comercial alimentaria para la que se pretendía lograr un equilibrio en el periodo del XI Plan. De especial interés en este sentido será la voluntad de lograr la autosuficiencia en trigo duro, un producto de gran importancia para la alimentación local pero del que existe una dependencia exterior que no se ha logrado eliminar ${ }^{52}$.

\subsection{Las políticas de oferta y demanda de productos agrícolas y la seguridad alimentaria}

El análisis de la implementación de las políticas agrarias en Túnez variará según se haga desde la perspectiva de la oferta o de la demanda. La gran dependencia exterior en productos básicos para la población como el cereal o el azúcar, la estructura de las exportaciones agrarias y la búsqueda de la autosuficiencia en otros productos básicos como la carne o la leche son características que hacen que la oferta y la demanda de productos agrícolas en Túnez sea muy sensible a la inestabilidad de los mercados internacionales y a la amenaza de productos más competitivos y baratos provenientes de otros mercados, en particular de la Unión Europea ${ }^{53}$.

Esta realidad, conviviendo con el objetivo de conseguir una seguridad alimentaria lo más elevada posible como elemento de soberanía, ha llevado a mantener sistemas de defensa de la producción agraria local frente a los productos similares disponibles en los mercados internacionales. Se mantienen medidas de protección aduanera tales como empresas estatales interviniendo en las importaciones y exportaciones de productos agrarios, y pese a los acuerdos de asociación con la UE y a los compromisos con la OMC, las restricciones fronterizas a las importaciones son elevadas, mediante tasas o cuotas. De esta modo, pese a las políticas globales de liberalización de los mercados y a la tendencia a la eliminación o reducción de barreras comerciales derivadas de los acuerdos internacionales -de la que se habla en los distintos Planes de desarrollo-, la protección mantenida por Túnez frente a productos agrarios importados sigue siendo elevada y las políticas de apoyo y mantenimiento de la agricultura local siguen siendo importantes (a través de precios garantizados y subvenciones a los inputs principalmente ${ }^{54}$ ) como se señala un reciente informe del Banco Africano de Desarrollo, considerándolas como una distorsión que crea ineficiencia económica $^{55}$. El logro de la seguridad alimentaria se ha entendido así como la consecución de la autosuficiencia mediante la protección de la producción interna, pese al discurso oficial mantenido en los Planes de adaptación a unos mercados internacionales cada vez más abiertos y competitivos.

Analizando los resultados de las políticas agrarias diseñadas en los últimos años, desde el punto de vista de la oferta los esfuerzos de mejoras en todos los ámbitos señalados (productividad, científico-técnicos, administrativos, regadíos, uso intensivo de inputs o factores de producción agrícola, etc.) se han hecho con el único objetivo de maximizar e incrementar la producción, no de optimizarla ${ }^{56}$. Se han obtenido mejoras relativas en las cifras de producción de determinados productos, pero sin llegar a cumplir con los objetivos establecidos y sin obtener las mejoras en la eficiencia necesarias para ser más competitivos en

\footnotetext{
${ }^{52}$ Hallam, Balby, op.cit. p. 10. Ver "XIIeme Plan...", op.cit,, p. 164.

53 "Distorsions...", op.cit., pp. 2 y 19.

54 "Perspectives des politiques agricoles...", op. cit., pp. 27 y sig.

55 "Distorsions...", op.cit., p. 1.

${ }^{56}$ Laajimi et al., op.cit., p. 25.
} 
los mercados internacionales. Al mismo tiempo, diversos indicadores revelan la debilidad de la contribución de la agricultura al crecimiento del conjunto de la economía ${ }^{57}$.

También desde el punto de vista de la oferta, una parte importante de las políticas públicas agrícolas se ha dirigido a garantizar las rentas al agricultor vía precios (no ayudas directas al productor, como en otros países emergentes) ${ }^{58}$. Para reducir la inestabilidad de los precios y mantener los ingresos de los agricultores se mantiene, por un lado, una política de precios mínimos garantizados por el Estado en productos como los cereales, la leche y el azúcar y, por otro, políticas públicas de almacenamiento e importación para regular excedentes o disponibilidad de productos ${ }^{59}$. También en este mismo sentido de mantener las rentas de los agricultores, se mantiene una política de subvenciones estatales a los inputs agrarios tales como semillas, abonos, fitosanitarios o maquinarias, que acompañan a las políticas de mejoras de regadíos que se incluyen en los Planes de desarrollo y a las primas a la inversión en agricultura.

Del lado de la demanda, se ha mantenido tradicionalmente una orientación de política alimentaria de "precios bajos" subvencionados para el consumidor, independientes del coste de producción de estos alimentos por la agricultura local o de su coste de adquisición en los mercados internacionales ${ }^{60}$. Aunque contraria a las tendencias liberalizadoras, la intervención estatal en los precios se ha reducido muy poco en los últimos años ${ }^{61}$. Los objetivos de esta política pretenderán limitar los efectos sobre los consumidores de las fluctuaciones de los precios en los mercados internacionales así como el riesgo de incremento de los costes de producción sobre los consumidores urbanos. En definitiva, se tratará de garantizar la seguridad alimentaria en términos de disponibilidad de alimentos básicos a la vez que se contribuye a mantener la estabilidad social, un aspecto esencial en estos países. El coste para las finanzas públicas de estas políticas será elevado, de manera que una parte importante del presupuesto está destinada directamente a compensar las diferencias entre los precios de producción/importación y los precios de consumo subvencionados; concretamente un 1,5 del PIB de Túnez en 2009 y el 1,1 en 2010 se destinaron a estas políticas a través de la Caja General de Compensación, montante que se incrementó en 2011 a cerca del 2\% del PIB como consecuencia de la decisión del Gobierno de Transición de aumentar el número de productos subvencionados y los presupuestos destinados a la Caja de Compensación, con el fin de tranquilizar a la población tras las revueltas de ese año ${ }^{62}$.

Si bien estas políticas han tenido un relativo éxito a lo largo del tiempo a la hora de garantizar la estabilidad social y de satisfacer razonablemente objetivos como el de la seguridad alimentaria entendida como disponibilidad de alimentos básicos, la cuestión principal que se plantea cara al futuro es la sostenibilidad del sistema en un contexto de creciente globalización y de liberalización de los mercados internacionales de productos agrarios en los que la agricultura Tunecina cada vez está más integrado. Así, más allá de las declaraciones recurrentes de los distintos Planes de desarrollo, las políticas de mantenimiento y protección de la agricultura de las que hemos hablado -que sólo se han reducido levemente en los últimos tiempos- plantean dudas sobre si son adecuadas por las distorsiones que

\footnotetext{
${ }^{57}$ Ibid. p. 26.

58 "Distorsions...", op.cit., p. 19.

59 Para detalle de estas políticas ver Lachaal, L.; Chebil, A.; Dhehibi, B. y Thabet, Ch. (2002): National Agricultural Policy Report for Tunisia, Medfrol Project, pp. 14-18; ver también "Distorsions...", op.cit., pp. 8-9.

${ }^{60}$ Laajimi et al., op.cit., p. 26.

61 "Distorsions...", op.cit., p. 19 y Lachaal, L., et al., op.cit., p. 8.

${ }^{62}$ Abis, op. cit., pp. 128-129.
} 
generan para un nuevo contexto nacional e internacional en el que Túnez se encuentra. ${ }^{63}$. Los avances relativos que presenta el sector agrario de este país desde una perspectiva macroeconómica no parecen haber conducido, según buena parte de expertos ${ }^{64}$, a un desarrollo duradero, y subsisten desafíos importantes tanto a la hora de alcanzar una mayor eficacia sostenible de la producción agraria (teniendo en cuenta recursos, inversiones, cambio climático y degradación medioambiental, envejecimiento, etc.), como a la hora de reducir la todavía existente brecha social entre el campo y la ciudad en ese país.

\section{El caso de Argelia}

Con un territorio dominado en su gran mayoría por extensiones de mesetas elevadas y el desierto del Sáhara, la superficie agrícola de Argelia abarca 39,9 millones de has., solo el 17\% de su territorio. A pesar de este reducido espacio, la agricultura supone un importante elemento de desarrollo económico y contribuye en la actualidad al Producto Interior Bruto (PIB) de Argelia en torno a un 12\%, -en la media mundial la agricultura aporta el 5\%- y emplea al $25 \%$ de la población activa, según los datos oficiales ${ }^{65}$.

Sin embargo, la producción agrícola de Argelia no es suficiente para abastecer la demanda nacional y sufre una fuerte carencia de productos agrícolas, que suponen, aproximadamente, el $20 \%$ del total de las importaciones. Es especialmente intensa su dependencia de productos como el azúcar, el té o el café, pero también de la leche, cuya producción solo cubre el $40 \%$ de la demanda nacional, o del trigo, que cubre el $35 \%$. Sus exportaciones agrícolas, fundamentalmente dátiles, vino y patatas, representan, aproximadamente, un $0,2 \%$ del total. ${ }^{66}$

Además, por las condiciones geográficas y climáticas de Argelia, la agricultura debe hacer frente a dos importantes obstáculos que siempre tendrán que ser tenidos en cuenta: la desertificación y la escasez del agua.

\subsection{Condicionantes históricos de las políticas agrarias en Argelia}

La agricultura no siempre ha sido el centro de las políticas prioritarias del Gobierno, especialmente por los mayores esfuerzos empleados en la industrialización tras la independencia del país, en 1962, y por los fuertes movimientos migratorios desde las áreas rurales a la ciudad.

Sin embargo, por encima de todos estos factores, ha sido el peso de la herencia colonial francesa el elemento que mayor obstrucción ha supuesto al desarrollo agrícola. ${ }^{67}$ Hacia finales del siglo XIX, la metrópoli francesa aprobó varias leyes por las que expropió a los campesinos argelinos 3,5 millones de has. de tierra arable de los 7,5 millones existentes. ${ }^{68}$

\footnotetext{
63 "Distorsions...", op. cit., p. 1.

${ }^{64}$ Laajimi, A. et al. op.cit. p. 28.

${ }^{65}$ Rapports Annuels sur le secteur, en http://www.minagri.dz.

${ }^{66}$ Hervie, Bertrand; Capone, Roberto; Abis Sébatien: "Changes and challenges facing agriculture in Maghreb", CIHEAM Analytic Note, $\mathrm{n}^{\circ} 16$ (2006).

${ }^{67}$ Sobre la colonización francesa de Argelia, véase, Côte, Marc (1988): L'Algérie ou l'espace retorné, París, Flammarion, 1988.

${ }^{68}$ La Organización de las Naciones Unidas para la Agricultura (FAO) define la tierra arable como la dedicada a cultivos anuales (cereales, patatas, legumbres, verduras, etcétera), frente a la tierra dedicada a cultivos
} 
Y si en un primer momento Argelia se autoabastecía con su propia producción, su agricultura se transformó para cubrir las necesidades de la metrópoli, algo que hoy en día sigue teniendo repercusión. Se introdujeron productos comerciales como el trigo, las uvas o los cítricos, en detrimento de los bosques, los cultivos tradicionales y las tierras de pasto, que experimentaron una gran reducción.

A partir de 1930, Argelia dejó de ser un país exportador de cereales y se convirtió en un país importador. Su producción no era suficiente para abastecer a su propia población. A pesar de que muchos argelinos no tenían acceso a alimentos suficientes para una dieta adecuada, las exportaciones de más de 17 millones de hectolitros de vino y las exportaciones de cítricos ayudaron a preservar el mito de una agricultura próspera y crearon la falsa ilusión de autosuficiencia, una percepción errónea que continúa hoy en día.

Desde la independencia de Argelia en 1962, se han aplicado distintas políticas agrícolas con el objetivo de impulsar el desarrollo de la agricultura y garantizar la seguridad alimentaria en el país. Sin embargo, es muy cuestionable si estas políticas han sido o no efectivas. ${ }^{69}$

Después de la declaración de independencia de Argelia en 1962, los colonos franceses abandonaron la mayor parte de las tierras de labranza fértiles, que fueron convertidas en granjas públicas. El Estado controlaba la gestión, las operaciones, la distribución y los precios de mercado. El sector aseguraba las exportaciones agrícolas (vino, cítricos y vegetales). ${ }^{70} \mathrm{Sin}$ embargo, la falta de incentivos a los trabajadores y un exceso de burocracia contribuyeron a que cayera la producción agrícola. Además, el sector privado fue completamente ignorado por el Gobierno. Se trataba de las tierras menos fértiles y ubicadas en lugares de difícil acceso, lo que explica que no hubieran sido expropiadas por los colonos franceses.

A partir de la década de los setenta, la nueva política del Gobierno buscó priorizar el sector industrial para propiciar el desarrollo del país. Así, el 55\% de las inversiones públicas se destinaron a la industria, frente al $8 \%$ dedicado a la agricultura. ${ }^{71}$ En cuanto al sector agrícola, el Estado expropió grandes explotaciones privadas y las redistribuyó entre los campesinos pobres y sin tierras. Sin embargo, la nacionalización del sector no logró una mayor productividad. La falta de incentivos a los agricultores de las cooperativas fue uno de los obstáculos al aumento de la producción. ${ }^{72}$

La ausencia de una política agraria coherente provocó un estancamiento de la producción agrícola. Sin embargo, la creciente dependencia de las importaciones de productos agrícolas llevó al Gobierno, a partir de 1980, a priorizar la revitalización del sector. Paulatinamente, el Estado se fue retirando del control de la agricultura y facilitó el acceso a la propiedad privada. Al mismo tiempo, el Ejecutivo argelino disminuyó los controles sobre el

permanentes (viñedos, olivares, frutales) y la tierra de pastos. Los dos primeros conceptos reciben el nombre de tierra cultivable, y el conjunto de los tres se denomina "tierra agrícola".

${ }^{69}$ Laoubi, Khaled y Yamao, Masahiro (2012): The Challenge of Agriculture in Algeria: Are Policies Effective?, Hiroshima, Hiroshima University, pp. 65-71.

${ }^{70}$ Bourdenane, N. (1991): Agriculture et alimentation en Algérie; entre les contraintes historiques et

les perspectives futures. Options Méditerranéennes, Série no 21. pp.145-157.

${ }^{71}$ Chemingui, Mohamed Abdelbasset (2003): What macroeconomics factors explain Algeria's poor economic growth performance, Background paper for the GDN global research project on explaining growth in developing countries: The case of Algeria.

${ }^{72}$ Laoubi, Yamao, op.cit., pp. 65-71. 
mercado, aceptó que los productores aumentaran los precios y permitió el acceso al crédito. ${ }^{73}$ Estas políticas abrieron la puerta a la economía de mercado.

A partir de 1987, Argelia comenzó a dar pasos reales hacia la transformación del sector agrícola, con una fuerte inversión en proyectos acuíferos con el objetivo de incrementar las zonas irrigadas. La inversión fue acompañada de reformas fundamentales para la liberalización del mercado agrícola: se permitió a los agricultores privados comprar productos al proveedor que eligieran; tanto los agricultores privados como las cooperativas empezaron a participar en el comercio al por mayor de productos agrícolas y se eliminó la propiedad de los municipios sobre ciertas tierras, que se pusieron a la venta. ${ }^{74}$

\subsection{Las políticas agrícolas en la actualidad y los desafíos pendientes}

Con la llegada del presidente Abdelaziz Bouteflika en 1999 la política agrícola se convirtió en uno de los principales objetivos del nuevo Gobierno ante el fracaso de las políticas anteriores, que no habían logrado una verdadera transformación del sector. La producción agrícola continuaba siendo insuficiente para abastecer el país y garantizar la seguridad alimentaria. Argelia era todavía un país eminentemente importador. El Programa Nacional de Desarrollo Agrícola, implantado en el año 2000, es el fruto de esta nueva perspectiva. En 2002 adquirió una dimensión rural -pasó a llamarse Programa Nacional de Desarrollo Agrícola y Rural (PNDAR)-, ante el interés del Ejecutivo argelino de propiciar el desarrollo de las áreas rurales.

El PNDAR se diseñó para responder a los problemas naturales, técnicos, organizacionales e institucionales responsables del debilitamiento de la seguridad alimentaria nacional, la degradación de los recursos naturales y la disminución de la cohesión y paz social en las áreas rurales, según describía el Ministerio de Agricultura y Desarrollo Rural de Argelia en 2007. Sus principales objetivos fueron el desarrollo y modernización de las granjas, la intensificación y la expansión de las áreas irrigadas, el desarrollo de la producción y productividad agrícola a través de grandes inversiones y el desarrollo sostenible. ${ }^{75}$

El gran impulso al desarrollo agrícola en Argelia se produjo con la Política de Renovación Agrícola y Rural, lanzada en 2009 y desarrollada en el Plan Quinquenal 20102014, que prevé una inversión de 10.000 millones de euros de recursos públicos en cinco años y 2.000 millones de euros anuales de inversión privada. ${ }^{76}$

Los principales objetivos marcados en el plan son:

- Aumento de la producción interna de bienes de consumo general para proporcionar una cobertura del $75 \%$ de las necesidades nacionales.

- La modernización y difusión de los avances tecnológicos en las explotaciones agrícolas (riego, fertilización, la mecanización, el uso de semillas).

- La modernización y organización de los sistemas de recolección y comercialización de la producción nacional.

\footnotetext{
73 Aghrout, Ahmed; Bougherira, Redha M. (2004): Algeria in transition: reforms and development prospects, Nueva York, Routledge Curzon.

${ }^{74}$ Laoubi, Yamao, op.cit., pp. 65-71.

${ }^{75}$ Para más información, léase Bessaoud, Omar (2002): "L’agriculture algérienne : des révolutions agraires aux réformes libérales (1963-2002)", en Blanc, Pierre et al.: Du Maghreb au Proche-Orient, les défis de l'agriculture, París, Budapest, Torino, L'Harmattan, pp. 73-99.

${ }^{76}$ Plan Quinquenal 2010-2014 para la Política de Renovación Agrícola y Rural en Argelia.
} 
- La generalización y extensión de los sistemas de riego para la agricultura en 1,6 millones de has. en 2014, frente a cerca de 900.000 has. de 2010.

- Un desarrollo de las zonas rurales, equilibrado, armónico y sostenible.

- Crecimiento de la producción agrícola media.

- Desarrollo de pequeñas y medianas empresas

- Creación de 1.200.000 empleos.

En definitiva, toda una serie de metas que se derivan de los tres ejes básicos en los que podemos resumir los fundamentos del plan $^{77}$ : 1.- desarrollo de programas de intensificación y de modernización con el fin de incrementar la producción y la productividad agrícola; 2.- la puesta en práctica de un sistema de regulación cara a asegurar y estabilizar la oferta de productos clave y asegurar una protección de los ingresos de los agricultores y los de los consumidores; 3.- la creación de un entorno que facilite y asegure las inversiones agrícolas.

\subsection{Las políticas de oferta y demanda de productos agrícolas y la seguridad alimentaria}

Como resultado del programa hasta 2012 , la nueva política agrícola ha contribuido a la creación de 900.000 puestos de trabajo. ${ }^{78}$ Después de décadas de descenso en el porcentaje de población que trabajaba en el sector rural, del $64 \%$ en la década de los setenta al $45 \%$ en la de los noventa, la población dedicada a la agricultura y la ganadería en Argelia ha crecido del $24 \%$ al $25 \%$ en los últimos diez años.

Sin embargo sus éxitos en el incremento de la producción agrícola no han sido tan positivos. A pesar de los esfuerzos realizados, el sector no ha crecido lo suficiente. Aunque se ha alcanzado la práctica autosuficiencia en productos como carne, patatas y tomates, a pesar de serios problemas de acaparamiento y carencias en la distribución, Argelia sigue teniendo una importante dependencia de las importaciones de productos básicos de consumo como el trigo y la leche, que, si bien han aumentado de forma notable su producción, solamente cubre alrededor del $40 \%$ de la demanda de la población. Otros productos básicos como el café, el té o el azúcar, siguen siendo importados prácticamente en su totalidad. La seguridad alimentaria, en línea con una política de soberanía alimentaria busca una disminución sustancial de las importaciones de alimentos.

En el ámbito de la oferta de alimentos el gobierno argelino ha incrementado la superficie cultivable recurriendo a arrendamientos de tierras agrícolas estatales, 2,5 millones de has., reforzando la productividad mediante el suministro al agricultor de semillas de alta calidad, apoyando la preservación de suelo y el uso de fertilizantes, introduciendo mejoras en la irrigación y gestión del agua, pretendiendo irrigar hasta el año 2014 más de 1,6 millones de has ${ }^{79}$, incrementando la mecanización con el recurso a créditos sin interés para el agricultor, así como la apertura a la inversión privada en tierras públicas.

Asimismo, está intentando diversificar las actividades económicas en el mundo rural para así mejorar el nivel de rentas así como favorecer de forma particular el nivel de renta de los pequeños agricultores. Para ello el gobierno ha establecido unos precios mínimos a recibir por los agricultores para los productos de amplio consumo. Así, el incremento de las

\footnotetext{
77 “L'Algérie veut garantir des prix minimum pour ses agriculteurs", Momagri, Regards sur l'actualité, 9 Julio 2012, en http://www.momagri.org.

${ }^{78}$ Laoubi, Yamao, op.cit., pp. 65-71.

79 "Évaluation de la mise en oeuvre du Renouveau rural: "Des indicateurs encourageants" selon le ministre", El Moudjahid, 8 Octubre 2012, en http://www.elmoudjahid.com/fr/actualites/33366.
} 
producciones de determinados alimentos en los últimos años (caso de patatas, carne blanca o cebollas, entre otros) ha ocasionado importantes caídas de los precios que recibe el agricultor por estos productos, amenazando seriamente los niveles de ingresos y la continuidad de explotaciones $^{80}$, por lo que se ha activado a mediados de 2012 el sistema de regulación de productos agrícolas de gran consumo (SYRPALAC), consistente en el almacenamiento de excesos de producción para garantizar los precios mínimos al agricultor. El sistema se inscribe en el marco de la citada política de Renovación Agrícola y Rural, que contempla la lucha contra la hipervolatilidad de precios agrarios y pretende proporcionar estabilidad a los ingresos de los agricultores como una condición esencial del desarrollo agrario del país ${ }^{81}$. No obstante, todavía existen quejas por parte de los agricultores en el sentido de que los precios de estos productos permiten una mera supervivencia de los agricultores.

En este contexto, subsisten importantes problemas inducidos por la subida de los precios y la especulación. Un importante desafío lo constituye la regulación de los precios de productos agrícolas de gran consumo para evitar la especulación. En este sentido se ha venido recurriendo a importaciones puntuales de productos de primera necesidad, que aparentemente podrían estar cubiertos mediante la producción interna, caso de la patata. Hay que citar también la necesidad de realizar más amplios esfuerzos en la mejora de los circuitos de distribución, incrementar de forma importante la eficiencia de los servicios aduaneros para las importaciones de productos agrícolas, afrontar las carencias en infraestructuras, así como las carencias en el almacenamiento de productos alimenticios y la necesidad de creación de stocks estratégicos. Las carencias logísticas de Argelia son superiores a las de los otros estados del Magreb con la excepción de Libia ${ }^{82}$.

En el ámbito de la demanda hay que señalar que el gobierno argelino ha desarrollado una política de importantes subvenciones a los productos alimenticios básicos. Rachid Benaissa, ministro de Agricultura, recientemente señaló la necesidad de mantener las subvenciones de productos de gran consumo como el pan, la leche, el aceite, el azúcar. El coste de esta política se evalúa en 300 mil millones de dinares anualmente ${ }^{83}$. Asimismo se han reducido las tarifas de importación y las tasas para productos de importación alimenticios. Este tipo de decisiones regulatorias, que se toman también en el marco de la Política de Renovación Agrícola y Rural, no se contemplan sólo por su alcance económico, sino que las propias autoridades las consideran como un instrumento necesario para mantener la estabilidad y la paz social ${ }^{84}$.

Uno de los problemas más graves a los que se enfrenta la agricultura en Argelia es el uso informal de los recursos acuíferos, es decir, enmarcado en la iniciativa privada y local pero fuera de las políticas nacionales. Aunque han permitido un cierto desarrollo agrícola, este desarrollo es insostenible, por la sobreexplotación de los recursos acuíferos y la salinización del suelo, cuyos impactos son ya visibles en algunas regiones del país como Bass-Cheliff. ${ }^{85}$ Los agricultores tienen dos alternativas: o invertir más dinero en realizar nuevas perforaciones para tener suficiente agua o hacer un uso sostenible de los recursos disponibles y adaptar sus cultivos. Pero hasta ahora, las políticas aplicadas han estado orientadas exclusivamente a

\footnotetext{
80 "L’Algerie veut garantir des prix minimum...", op.cit. p.1.

${ }^{81}$ Idem.

${ }^{82}$ African Development Bank (2012): The Political Economy of Food Security in North Africa, p.19.

83 Tazerout, Idir: “L'Algérie doit maintenir ces subventions”, L'Expression, 21 Diciembre 2011, en http://www.lexpressiondz.com/actualite/144908-1-algerie-doit-maintenir-ces-subventions.html.

${ }^{85}$ African Development Bank (2011): Agricultural Use of Groundwater and Management Initiatives in the Maghreb.
} 
impedir las perforaciones. Es fundamental el diseño de estrategias para una explotación sostenible de los acuíferos con políticas que incluyan a todos los actores implicados, desde organizaciones responsables del uso del agua a organizaciones agrícolas y, sobre todo, los propios profesionales.

Asimismo otra crítica importante a los planes argelinos es precisamente la burocratización. Se trata de planes dirigidos desde arriba que no permiten a los agricultores el desarrollo de una mayor autonomía, a pesar de que según cálculos, de las 1.1 millones de explotaciones agrícolas, unas 800.000 pertenecen a agricultores privados ${ }^{86}$.

Con este balance, la estrategia de desarrollo agrícola en Argelia debe afrontar todavía numerosos retos, entre los que podemos destacar los siguientes: 1.- Mejorar el marco legal y normativo en el uso de los recursos agroecológicos. 2.- Promover un mercado transparente en cuanto a la concesión y arrendamiento de tierras agrícolas. 3.- La implementación de un sistema de seguros y financiación de cultivos. 4.- Mejorar la formación de los agricultores y la investigación. 5.- Desarrollar sistemas de control de la producción y la industria agrícola para orientar la producción y reducir la dependencia alimentaria. 6.- Continuar con el apoyo a pequeños y medianos agricultores. 7.- Mejorar el sistema de incentivos para la agricultura, orientados a aumentar la producción agrícola, especialmente en los productos más competitivos, lo que contribuirá al incremento de las exportaciones no petroleras. 8.Desarrollar los sistemas logísticos y de distribución. 9.- Fomentar la iniciativa privada. 10.Hacer frente a los desafíos medioambientales y la desertización.

En definitiva, aunque han existido mejoras relevantes del sector agrario argelino en los últimos años, los desafíos pendientes son muy numerosos y en todos los ámbitos, desde la organización y regulación, el fomento de la iniciativa privada y la financiación, hasta la logística y la formación del agricultor, pasando, por supuesto, por la constante mejora de las producciones, esencial para conseguir esa soberanía alimentaria planteada desde las políticas gubernamentales.

\section{El caso de Marruecos}

La evolución del sector agrícola marroquí constituye un elemento de primer orden a la hora de analizar el desarrollo económico del país, el equilibrio entre el campo y la ciudad, la cohesión social y la sostenibilidad medioambiental.

El peso global de la agricultura en la economía de Marruecos se hace evidente al analizar su impacto en la riqueza nacional, suponiendo la agricultura en el año 2011 el $13,25 \%$ del Producto Interior Bruto (PIB) total ${ }^{87}$, que si añadimos el peso de la agroindustria se incrementa hasta $19 \%^{88}$. Su incidencia en términos de empleo llega al $40,3 \%$ de la

\footnotetext{
86 "Agriculture: Prédominance du privé", El Moudjahid, 13 Mayo 2012, en http://www.elmoudjahid.com/fr/actualites/27703.

${ }_{87}$ Haut-Commissariat au Plan: "Comptes Nationaux Provisoires 2011 (base 1998)", (Junio 2012), p. 6, en http://www.hcp.ma/file/124922/.

88 Dato de 2010; ver Barrena Casamayor, Irene: "Informes Sectoriales: Oportunidades de inversión y cooperación empresarial. El sector de la Agricultura en Marruecos: inversión para empresas españolas agrícolas", Oficina Económica y Comercial de la Embajada de España en Rabat, (Agosto 2010), p. 11.
} 
población total activa y el $76,4 \%{ }^{89}$ de la población rural dependen exclusivamente del sector agrícola. En cuanto a su participación en la conformación de la balanza comercial, las exportaciones agrarias fluctúan entre el $15 \%$ y el $21 \%$ de las exportaciones totales, conformando el $19 \%$ de las importaciones ${ }^{90}$.

En este contexto, cabe destacar la importancia de las políticas agrícolas implementadas por Marruecos desde su independencia hasta la actualidad. Sin embargo, no debemos limitar el análisis de las políticas agrícolas marroquíes a su rol en la economía nacional, ya que su relevancia trasciende el ámbito meramente económico.

La agricultura en Marruecos debe ser comprendida como un fenómeno de múltiples caras. Una construcción heterogénea que se asienta sobre la base de una diversidad de factores estrechamente relacionados entre sí evocando un concepto multidimensional, en el que se hacen presentes aspectos sociales, económicos y medioambientales, y en el que se pone de manifiesto la especial relevancia de la seguridad alimentaria.

\subsection{Factores condicionantes de la actividad agrícola}

La política agrícola desarrollada por Marruecos desde su independencia en 1956 hasta la actualidad, debe hacer frente a los factores estructurales que condicionan una actividad agrícola entendida, en ocasiones, como contradictoria ${ }^{91}$ dada su gran complejidad. Estos factores, de carácter económico, social/cultural y climáticos/medioambientales, serán tenidos en cuenta en el desarrollo y la implementación de las políticas agrícolas, primando en mayor o menor medida unos elementos sobre los otros dependiendo de la coyuntura en la que se producen.

\section{1) Factores sociales/culturales:}

En Marruecos el sistema de tenencia de la tierra no se corresponde con criterios técnicos o de productividad, sino con el mantenimiento de unos determinados usos y costumbres tradicionales que han derivado en unas estructuras de propiedad de carácter minifundista en gran medida. La presión demográfica y el sistema de distribución de la tierra por herencia ha contribuído a la fragmentación de las explotaciones privadas. Así, en el Censo Agrario General de 1996 el 71,1\% de las explotaciones agrícolas tenía una extensión menor de cinco has., y el 25,4\% de estas tenían menos de una hectárea ${ }^{92}$.

\section{2)Factores climáticos/medioambientales:}

La agricultura marroquí se encuentra ampliamente condicionada por los factores climáticos que repercuten en la desigual disposición de los recursos hídricos. Las fluctuaciones anuales en el régimen de lluvias contribuyen a la desestabilización de las cosechas y a la volatilidad de las exportaciones, poniendo de manifiesto una situación de

\footnotetext{
${ }^{89}$ Haut-Commissariat au Plan du Maroc, Centre National de Documentation (2009): Emploi par branche d'activité de la population active occupée au niveau national" y "Emploi par branche d'activité de la population active occupée au milieu rural”, en http://www.hcp.ma/Emploi-Ventilation-par-Branche_r68.html.

90 "Barrena Casamayor", op.cit. p. 11.

${ }^{91}$ Akesbi, Najib: "La política de ajuste estructural en la agricultura marroquí (De la "política de pantanos" a la liberalización), Economía Agraria, no. 172 (1995), p. 77.

${ }_{92}$ Aznar, J. Ángel: "El sector agrario en Marruecos", Boletín Económico de ICE, n 2747 , (11 al 17 de Noviembre de 2002), pp. 23-33.
} 
insuficiencia alimentaria ${ }^{93}$. Además, la presión urbanizadora y la propia geografía del territorio marroquí limitan las posibilidades de explotación de la tierra, reduciéndose la superficie agraria útil al $11 \%^{94}$ del total.

\section{3)Factores económicos:}

Durante los últimos años hemos asistido a una pérdida de peso de la agricultura en el PIB, que ha pasado del $40 \%$ en $1960^{95}$ al $15 \%$ actual, y a una limitación de su impacto en el desarrollo económico del país, que se ha acusado en los últimos años de malas cosechas. Sin embargo, la evolución del sector agrícola en Marruecos sigue condicionando fuertemente el resultado total de la economía, con un papel fundamental en el equilibrio rural y la estabilidad campo/ciudad.

\subsection{El desarrollo de la política agraria}

Desde la independencia de Marruecos, el Estado ha tratado de llevar a cabo una política ampliamente intervencionista en el sector agrícola como mecanismo para lograr la autosuficiencia alimentaria y la independencia económica.

En 1960 el 70\% de la población vive de la agricultura, que genera el $40 \%$ del PIB y supone el $80 \%$ de las exportaciones totales ${ }^{96}$. Sin embargo, mientras que la estructura productiva del país está ligada a la actividad agrícola, persiste una situación de subdesarrollo estructural y falta de modernización que, unido a la elevada parcelación de la tierra, ha repercutido directamente en el escaso nivel de productividad de los cultivos.

La Reforma Agraria iniciada en el año 1960 será la primera que aborde, aunque con resultados muy limitados ${ }^{97}$, el intento de modernización de la agricultura mediante una gran reforma estructural de carácter industrialista que, sin embargó, no abordará la cuestión de la estructura agraria.

Aparece por primera vez, a pesar de la primacía de una política exportadora, un interés en orientar la produccion hacia la demanda interna asociado al concepto de autosuficiencia alimentaria, y la articulacion de una política agrícola nacional ligada a un modelo de producción basado en el proteccionismo y la sustitución de importaciones.

Sin embargo, los escasos resultados de la Reforma Agraria favorecerán una nueva aproximación a la agricultura de carácter más "técnico que político", basada en la rentabilización de la tierra mediante la extensión del regadío y la realización de grandes obras hidraúlicas. Se inicia así la "política de pantanos"98, como uno de los grandes intentos de la modernización del sector, la intensificación de la producción y la superación de la climatología como uno de los grandes condicionantes de la actividad agrícola en Marruecos.

\footnotetext{
${ }^{93}$ La producción agrícola en Marruecos puede llegar a duplicarse de un año a otro por incidencia de la sequía, así en el año 2005 la producción se limitó a unos modestos 4 millones de toneladas para alcanzar los 10 millones el año siguiente. Como ponen de manifiesto en la Ficha Económica de Marruecos las autoras Beatriz Cerezo, Rosalva Espino y Cristina Silvera, en un año de mala campaña agrícola, como fue el 2009, las malas cosechas provocaron una caída del $7,1 \%$ en el PIBA.

${ }_{94}$ Aznar, op. cit., pp. 23-33.

95 Juárez, Francisco: "Reforma agraria y modernización en la agricultura de Marruecos", Agricultura y Sociedad, no 47 (Abril-Junio 1988), pp. 177-209.

${ }^{96}$ Ibid., pp. 177-209.

97 "La política de ajuste...", op.cit., p. 79.

${ }^{98}$ Ibid., p. 80.
} 
El elemento central de la política agraria del momento se articulará en torno a la utilización del regadío como elemento central para la modernización de la agricultura, la mejora del rendimiento de las explotaciones agrícolas y el aumento de productividad, con el horizonte en el año $2010^{99}$, cuando se preveía que la superficie equipada con obras hidráulicas alcanzara $1.400 .000 \mathrm{Ha}^{100}$. La política de regadío ha tenido en general efectos positivos sobre la producción agrícola mejorando notablemente el rendimiento de las explotaciones: el regadío supone el 15\% de la superficie agraria útil, el $45 \%$ del valor añadido agrícola y hasta dos tercios del empleo en el medio rural ${ }^{101}$.

Acompañando a esta "política de pantanos" aparece un proyecto de intervención estatal a gran escala en la agricultura, de la mano de las grandes empresas públicas y una serie de instrumentos de intervención directa que podemos clasificar en tres categorías: aquellos encaminados a garantizar la producción agrícola (la creación de un sistema de crédito y las subvenciones de los inputs agrícolas), los destinados a garantizar el autoabastecimiento y necesidades de la población (el establecimiento de unos "cultivos obligatorios" que mantuviese un flujo continuo de exportaciones a la vez que garantizaba la oferta interna, el control de precios de los productos básicos y el desarrollo de un sistema de regulación del comercio interno) y los instrumentos de carácter proteccionista (el control de las importaciones mediante un poderoso sistema arancelario de carácter proteccionista, le organización de las exportaciones mediante la acción de la Oficina de Comercialización y Exportación).

La década de 1980 se inicia con un desmantelamiento progresivo del entramado de protecciones agrícolas desarrollado por el Estado, favorecido por la intervención del Banco Mundial y el Fondo Monetario Internacional en la economía marroquí, mediante el Programa de Ajuste Estructural. La transición a una economía de mercado supone la entrada masiva de capital privado en un sector que hasta entonces había gozado de un tratamiento privilegiado. La liberalización económica y la apertura a los mercados internacionales ponen fin a la iniciativa estatal en el sector agrícola suprimiendo el sistema de garantías previo. Con la liberalización comercial aparece un nuevo desafío: la seguridad alimentaria asociada a las incertidumbres que plantea el nuevo escenario económico.

La liberalización de precios de los inputs agrícolas ha provocado un encarecimiento que repercute en el precio final del producto, la eliminación de los planes de cultivo unido a la inclusión en el comercio internacional de Marruecos y su cercanía al mercado europeo ha repercutido en el desvío de cosechas y la desregulación interna ha contribuido en el aumento de precios de los productos básicos ${ }^{102}$.

En este contexto, se ha producido en los últimos años un aumento considerable de las importaciones de alimentos básicos. Las importaciones netas de cereales y ayuda alimentaria (como porcentaje sobre el total del consumo) ya suponen el 54,1\% en Marruecos ${ }^{103}$, lo que ha contribuido a aumentar su dependencia externa disminuyendo la seguridad alimentaria y

\footnotetext{
${ }^{99}$ Si bien Najib Akesbi destaca que el objetivo inicial era contar con un millón de hectáreas para el año 2000, este objetivo ya se había alcanzado en1996, con una superficie total de regadío fue de 1.251.456 ha.

${ }^{100}$ Aznar, op.cit. p. 25.

101 Aznar, op.cit. cita a Azizi, A. et el Hendir, R. (1999): "Impact de l'irrigation sur l'environnement dans les grands périmètres irrigués du Maroc et développement d'un modèle SIG (sous ARC/INFO) pour le diagnostic et la gestion de l'environnement dans l'ORMVA de Tadla". Rabat. V, Ed. Institut Agronomique et Vétérinaire Hassan II, pp. 23-33.

${ }_{102}$ Aznar, op.cit. pp. 23-33.

${ }^{103}$ Marquina, Antonio (2004): "Environmental Challenges in the Mediterranean 2000-2050", Dordrecht, Boston, Kluwer Academic Publishers.
} 
aumentando los desequilibrios económicos y sociales, siendo este un fenómeno que se agravará con el paso de los años.

\subsection{El Plan Marruecos Verde}

La política de liberalización económica llevada a cabo por Marruecos, favoreciendo la intervención del sector privado y reduciendo las subvenciones estatales, fracasó a la hora de corregir factores como la fragmentación, el reducido tamaño de las explotaciones y la mala repartición de la tierra.

Para un sector de la importancia de la agricultura, que considera la seguridad alimentaria un objetivo estratégico, quedó de manifiesto que los planes nacionales de desarrollo agrícola diseñados hasta ese momento eran insuficientes y poco efectivos ante un nuevo contexto de mayor inestabilidad de precios agrícolas a nivel mundial. Especialmente resulta evidente si se tiene en cuenta que el sector agrícola sufre de profundos problemas estructurales y las políticas de desarrollo rural implementadas no sólo no tuvieron éxito en disminuir el déficit estructural en la balanza comercial agrícola y la situación de dependencia alimentaria, sino que dejaban patente su vulnerabilidad ante las fluctuaciones climáticas, las presiones de la liberalización del comercio y la ya clara volatilidad de los precios de los productos agrícolas a nivel mundial.

Esta falta de resultados explicaría en buena medida el lanzamiento de una nueva iniciativa presentada por Marruecos en el año $2008^{104}$ : el Plan Maroc Vert. Como se señala en el propio Plan, "la agricultura constituirá el principal motor de crecimiento de la economía nacional en los próximos 10-15 años, con unos impactos colosales en términos de crecimiento del PIB, de creación de empleos, de exportación y de lucha contra la pobreza"105. Así pues, esta nueva estrategia vuelve a situar una vez más a la agricultura como motor del crecimiento económico del país, mediante un incremento del PIB de 70 a 100 miles de millones de Dirhams, y del desarrollo social y la lucha contra la pobreza, incrementando los ingresos de los agricultores y garantizando su sostenibilidad.

El Plan se asienta sobre dos pilares, un primer pilar que trata de desarrollar una agricultura moderna, mediante el "desarrollo agresivo de una agricultura de alto valor añadido y alta productividad", competitiva comercialmente, siendo el alto valor añadido la pieza central del desarrollo económico y en el posicionamiento estratégico de las exportaciones, con reformas orientadas a la mejora de la gestión del terreno, en un intento de superar la parcelación de la tierra ${ }^{106}$, buscando la atracción de capital privado, organizada en núcleos de superficies superiores a las 100 has a los que pudieran añadirse otras explotaciones pequeñas y medianas para conseguir sinergias importantes, pudiendo alcanzar un tamaño de agregación de entre 200 y 2000 has, con inversiones privadas, descansando sobre una doble contratación, la primera entre el agregador y el Estado marroquí y la segunda entre el agregador y los otros productores agregados. El conjunto se prevé que pueda afectar a 540.000 agricultores. Un segundo pilar, de "acompañamiento solidario de la pequeña agricultura", centrado en los

\footnotetext{
${ }^{104}$ Ya en el año 2002 se había lanzado la Estrategia 2020 de Desarrollo Rural como predecesora del Plan Marruecos Verde, pero su incidencia en la modernización de la agricultura tuvo un alcance muy limitado, ya que únicamente se centró en la apertura de la agricultura marroquí al sector privado mediante las licitaciones de tierras estatales. Esta estrategia fue rápidamente sustituida por el nuevo plan.

${ }^{105}$ Agencia para el Desarrollo Agrícola del Gobierno de Marruecos: "Plan Marruecos Verde", 2008, consultar en http://www.ada.gov.ma/es/Plan_Maroc Vert/plan-maroc-vert.php.

${ }_{106}$ Aparece el concepto de "agregación" como sistema de organización de la agricultura, con una fuerte orientación hacia la securitización del abastecimiento interno.
} 
pequeños y medianos agricultores, con numerosas explotaciones no competitivas, teniendo como objetivo la lucha contra la pobreza y una mejora de las rentas de los agricultores en las zonas más desfavorecidas afectando a unas 560.000 explotaciones, tratando de disminuir la brecha entre el campo y la ciudad, fomentando la cohesión social e incluyendo tres tipos de proyectos: proyectos de reconversión, pasando de explotaciones agrícolas precarias de cereales a producciones de mayor valor añadido; proyectos de diversificación que generen rentas complementarias; proyectos de intensificación con mejores técnicas capaces de mejorar los rendimientos ${ }^{107}$. Se trata de cuatro ejes fundamentales: el desarrollo de un plan de inversiones que combine la acción estatal con una intervención efectiva del sector privado, un plan de subvenciones agrícolas y fomento de la cooperación, un plan de generación de productos de alto valor añadido con proyección nacional e internacional y un plan orientado a la optimización de los recursos hídricos y la protección de los recursos naturales ${ }^{108}$.

Se trataría, así, de desarrollar una nueva estrategia de crecimiento económico y desarrollo social que solucione de una vez por todas las grandes contradicciones de la agricultura marroquí, llevándola a un nuevo estadio de modernidad; tomando en consideración también las dimensiones medioambientales y el cambio climático.

\subsection{La implementación de las políticas agrarias y la seguridad alimentaria}

Las políticas agrícolas implementadas por Marruecos hasta fechas recientes han adolecido de una falta de visión global y se han visto fuertemente influidas por factores económicos y sociales, así como por el contexto internacional, buscando acciones limitadas sobre aspectos concretos de la agricultura que han retrasado cada vez más la oportunidad de afrontar los grandes desafíos a los que se enfrenta el país. La fragmentación de las estructuras de propiedad y la limitada industrialización repercuten en la escasa productividad. La presión demográfica creciente, la incapacidad de desarrollar una política de producción que cubra la demanda interna y la falta de articulación del mercado nacional han incrementado la dependencia exterior del país, agravando la inseguridad alimentaria.

Algunos aspectos, como la necesidad de gestionar los recursos hídricos de una forma más eficiente y de favorecer la mejora de la productividad de las explotaciones ha llevado a la implementación de una política de inversiones masivas en infraestructuras con una notable mejora de los rendimientos agrícolas ${ }^{109}$, que se inicia en la década de 1960 y continúa en la actualidad.

Esta estrategia de consecución de soberanía alimentaria mediante un control apropiado de los recursos naturales y la mejora de la producción, se ha acompañado de una serie de instrumentos dirigidos a garantizar la autosuficiencia de la población. Medidas como la creación de un sistema de crédito agrícola, el control de precios, las subvenciones de los inputs, el establecimiento de unos "cultivos obligatorios" "110 y la articulación de un sistema de "circuitos logísticos de distribución y el acceso a los mercados""111, que será ampliamente

\footnotetext{
${ }^{107}$ Najib Akesbi: "Une nouvelle stratégie pour l'agriculture marocaine: Le Plan Maroc Vert", New Medit nº 2 , (2012), p. 13.

108 A pesar de que el Plan se asienta sobre siete cimientos de acuerdo a la estructura de la Agencia para el Desarrollo Agrícola, hemos preferido utilizar la división elegida por Ruiz de Alda en las Notas Sectoriales de la Oficina Económica y Comercial de la Embajada de España en Rabat: "El mercado de la maquinaria agrícola en Marruecos", (Septiembre 2010).

109 Aznar, op.cit. pp. 23-33.

${ }^{110}$ Ibid.

${ }^{111}$ Mensaje real (de SM el Rey Mohammed VI) a la segunda edición del Foro Internacional "Dakar-agrícola" (Abril 2011), en http://www.maroc.ma/PortailInst/Es/Actualites/Competencia.htm.
} 
reforzado en el Plan Maroc Vert, contribuirán a "proteger la producción interior, particularmente la de productos continentales tradicionales como los cereales o los productos animales, en los cuales Marruecos no podía competir en los mercados internacionales" 112 así como a "mantener los precios de los productos de primera necesidad a niveles accesibles para la población""113.

También se llevará a cabo, en un primer momento, el desarrollo de una política económica de carácter ampliamente proteccionista, mediante un sistema de sustitución de importaciones y control de precios, que se agotará rápidamente ante las nuevas tendencias liberalizadoras y la apertura a los mercados internacionales y sus inercias, aumentando así, la dependencia externa y los desequilibrios económicos y sociales, comprometiendo la consecución de los objetivos de la seguridad alimentaria.

En este contexto, el Plan Marruecos Verde ofrece por primera vez una visión global del desarrollo agrícola como elemento vertebrador del desarrollo y la modernización del país, con la seguridad alimentaria como elemento central de una estrategia basada en "la instauración de un equilibrio entre el desarrollo humano y la gestión racional de los recursos naturales"114.

Sin embargo, a pesar de que todavía es muy pronto para determinar los resultados del Plan, existen algunas cuestiones en las que merece la pena detenerse. En primer lugar, el planteamiento del Plan Maruecos Verde parece notablemente centrado en aspectos técnicos y productivos, siendo la agricultura un sector de actividad que les sobrepasa, dadas sus características peculiares y su multidimensionalidad ${ }^{115}$, con implicaciones no sólo económicas y sociales, sino también en el medioambiente, el desarrollo territorial, el equilibrio campo/ciudad, la lucha contra la pobreza o el patrimonio cultural.

La agricultura marroquí, esencialmente familiar, ha sobrevivido a los cambios en las políticas agrícolas marroquíes, y, a pesar de su baja industrialización, continúa siendo el principal medio de subsistencia en el ámbito rural así como la primera fuente de empleo, por lo que llama la atención que el Plan no se haya centrado en su productividad y competitividad. Además, se tendrían que considerar los efectos sobre ella de la "gestión acelerada del terreno" 116 , una política que fomenta el desarrollo de esa agricultura de alto valor añadido en explotaciones de gran tamaño, independientemente de los problemas que la "agregación" está presentando. En ese sentido, también habría que considerar la incidencia del denominado "desarrollo agresivo de una agricultura de alto valor añadido y alta productividad" sobre el equilibrio medioambiental, que apenas está presente. Por último, no está claro qué parte de la producción agrícola se dedicará a cubrir la demanda interna, dado el claro privilegio que recibe la política de exportación orientada hacia el mercado europeo, pero que no contribuye a remediar la situación de dependencia alimentaria. El dualismo del Plan Maruecos Verde -con una agricultura moderna, productiva y con explotaciones grandes por una parte, y una agricultura tradicional por otra- hará que la brecha entre dos agriculturas se agrande, independientemente de las críticas a los planteamientos elitistas que hacen del segundo pilar

\footnotetext{
112 Escribano Francés, Gonzalo y Lorca Corróns, Alejandro: "La política comercial de Marruecos: de la liberalización a la modernización”, Marruecos, ICE, no 819, (2004). p. 69.

113 Ibid.

${ }^{114}$ Mensaje real (de SM el Rey Mohammed VI) a la segunda edición del Foro Internacional "Dakar-agrícola". Abril 2011. http://www.maroc.ma/PortailInst/Es/Actualites/Competencia.htm

115 "Une nouvelle stratégie...", p. 15.

${ }^{116}$ Santiago Alcelde, J.J.(2011): "Efectos de los acuerdos comerciales agrícolas entre Marruecos y la UE sobre la población marroquî́, Fundación Cajamar, Documentos de trabajo (2011/01), p. 27.
} 
-la pequeña y mediana agricultura- una especie de vertedero del primer pilar, y que también parece diseñado para absorber los daños producidos por el primer pilar.

\section{Conclusiones}

Aunque Túnez, Argelia y Marruecos ya no se pueden definir como economías agrícolas, nos encontramos ante tres países cuyo sector agrario sigue teniendo una gran importancia, no sólo por su significativa participación en la formación del Producto Interior Bruto nacional o por el importante volumen de empleo que genera en el ámbito rural, sino también por el papel esencial que este sector tiene a la hora de dar respuesta a las necesidades de alimentos de la población de estos países, dicho de otro modo, por su contribución a la seguridad alimentaria, un concepto que de una forma $u$ otra ha estado presente como objetivo en las distintas políticas agrícolas que Túnez, Argelia y Marruecos han tratado de desarrollar para modernizar sus agriculturas desde el mismo momento de sus independencias.

Desde un punto de vista general, aunque con algunos desfases temporales entre ellos ${ }^{117}$, estos tres países han abordado las políticas agrícolas siguiendo etapas similares: después de un periodo de intervencionismo en el que se planearon reformas agrarias y/o grandes infraestructuras hidráulicas, los ajustes estructurales de sus economías exigidos por el Fondo Monetario Internacional condujeron a una reducción del papel del Estado, que, no obstante, sigue siendo muy importante en algunos casos, manteniéndose hasta la actualidad medidas de regulación de oferta y demanda de determinados productos básicos; tras un proceso de cierta liberalización interna, llegó el momento de una liberalización cara al exterior, dentro del marco de los acuerdos y las negociaciones con la Organización Mundial de Comercio y con los acuerdos con la Unión Europea, que se ha convertido en uno de principales socios comerciales de los países de la región.

Así, las políticas agrarias han ido evolucionando y contemplando las distintas realidades nacionales e internacionales de un contexto cada vez más complejo, en el que se hacen visibles los riesgos para la seguridad alimentaria como objetivo gubernamental esencial, que algunos de esos países como Argelia o Túnez, también consideran como un elemento de soberanía. Aspectos como la debilidad del sector agrario, el atraso y su escasa productividad, la falta de competitividad y de inserción en el mercado, la vulnerabilidad ante la competencia internacional y ante la volatilidad de los precios, o la fuerte dependencia de algunos productos esenciales que necesitan importar, caso del cereal, son cuestiones que las distintas políticas agrarias intentan enfrentar, con planes y documentos donde aparecen directrices, líneas de acción y medidas ambiciosas sobre el papel, pero que han obtenido hasta ahora resultados mixtos.

Si en general estos países han conseguido con sus políticas ciertas mejoras en el entorno en el que se desarrolla la actividad agraria y se han conseguido incrementos de producción notables en algunos países y alimentos -aunque no suficientes para cubrir la demanda interna de algunos productos básicos-, subsisten en las agriculturas de estos países importantes desafíos en todos los ámbitos, desde la regulación y la modernización técnica, hasta las posibilidades de comercialización y logística, pasando por la misma sostenibilidad de la producción y de los recursos naturales que se utilizan, o el riesgo de distanciamiento entre una

\footnotetext{
${ }^{117}$ Blanc, Pierre: "Enseignements et défis pour le futur agricole au Maghreb et en Egypte", en "Perspectives des politiques agricoles...", op.cit., p. 175.
} 
agricultura moderna y productiva que se pretende fomentar frente a una agricultura tradicional, que es la base de la estructura agraria en países como Túnez y Marruecos.

El objetivo de la seguridad alimentaria se configura por tanto como elemento esencial en las políticas agrarias de los tres países, lo que se refleja no sólo en la voluntad de incrementar producciones y en el deseo de autosuficiencia, sino que está presente también en otras medidas relacionadas con la oferta, como son los mecanismos para garantizar las rentas de los agricultores que se mantienen en los tres países, así como medidas en el ámbito de la demanda, facilitando subvenciones y acceso suficiente y a precios bajos a productos de consumo básico para la población en general, cuya disponibilidad y estabilidad en el precio es muy importante para mantener la estabilidad y la paz social. 